\title{
Accessory Renal Artery
}

National Cancer Institute

\section{Source}

National Cancer Institute. Accessory Renal Artery. NCI Thesaurus. Code C116183.

An additional renal artery originating from the aorta. Accessory renal arteries are found in 26-30\% of humans. 